Saudi Journal of Oral and Dental Research

Abbreviated Key Title: Saudi J Oral Dent Res

ISSN 2518-1300 (Print) |ISSN 2518-1297 (Online)

Scholars Middle East Publishers, Dubai, United Arab Emirates

Journal homepage: https://saudijournals.com

Review Article

\title{
Tooth Surface Loss: Definitions, Prevention and Diagnosis
}

Abdulaziz A. Algadhi BDS, MClinDent ${ }^{1 *}$

${ }^{1}$ Restorative Department, College of Dentistry, Jazan University, Jazan, Saudi Arabia

DOI: $10.36348 /$ sjodr.2021.v06i03.005

| Received: 27.02.2021 | Accepted: 15.03.2021 | Published: 16.03.2021

*Corresponding author: Abdulaziz Algadhi

\section{Abstract}

Background: Tooth surface loss (TSL) is the loss of dental hard tissue including enamel and dentin caused by factors other than dental caries. This condition can be seen clinically as attrition, erosion, abrasion and abfraction. TSL can cause dental hypersensitivity and loss of vertical dimension. Also, TSL can be asymptomatic in which patients are not aware of the condition. Aims: This review will provide an overview of the definitions, prevalence, aetiology, diagnosis and preventive management of TSL. Conclusion: TSL or tooth wear (TW) is a common physiological condition occurs throughout the patients' life, however, excessive tooth wear that cause functional and aesthetic problems are considered pathological wear. Dentists should be aware of the aetiology of the tooth wear in order to provide a successful diagnosis, management, and treatment. Clinical significance: it is of paramount importance to know and differentiate between the causes of the TW to be able to prevent and treat the problem. In mild to moderate TW without functional and aesthetical concerns, preventive measurements and regular follow-up will help to monitor and prevent further destructions.

Keywords: attrition, erosion, prevention, tooth surface loss, tooth wear.

Copyright () 2021 The Author(s): This is an open-access article distributed under the terms of the Creative Commons Attribution 4.0 International License (CC BY-NC 4.0) which permits unrestricted use, distribution, and reproduction in any medium for non-commercial use provided the original author and source are credited.

\section{INTRODUCTION}

Tooth wear (TW) is a condition affecting the dental hard tissues $[1,2]$. TW is a general term describing the loss of the tooth surfaces from factors other than dental caries. (3) The normal physiological TW is irreversible condition and cumulative with age [2]. Lamberchts et al., in 1989 found that the normal physiological wear in enamel is $20-38$ um per year [4].

Pathological TW caused by different aetiological factors such as erosion, abrasion, attrition and abfraction [2]. Tooth surface loss (TSL) term was suggested by Eccles to include all the causative factors regardless of the exact cause of wear [5]. This term makes it easy to describe the condition due to the difficulty to isolate one single factor when a patient come with TW. TSL include factors such as dentinogenesis imperfecta, amelogenesis imperfecta and trauma [2].

Pathological TW can range from mild sensitivity caused by abrasion or erosion to large destruction of teeth caused by attrition. Furthermore, treatment of TW can range from simple preventive care to full mouth rehabilitation [1].

\section{Definitions}

TW is multifactorial conditions, it can be subdivided into: Attrition, Erosion, Abrasion and Abfraction.

Attrition is the loss of tooth tissue or restoration caused by masticatory forces between opposing teeth. Attrition occur on the incisal and occlusal contacting surfaces [6]. The early clinical sign of attrition is the appearance of small facet on the cusp or slight flattening in the incisal edge. In severe attrition cases, shortening of the clinical crown with dentin and pulp exposure can be seen [2].

Erosion is the loss of tooth substances by chemical process. Chronic exposure of dental tissues to acidic substrate can cause dental erosion. The early clinical sign can present as a shallow smooth surface affecting the enamel. In severe cases a cupping on the occlusal surface of posterior teeth and incisal edge of anterior teeth can be seen $[2,3]$.

Abrasion is the physical TSL caused by mechanical process. Abrasion includes an object or material repeatedly contacting the tooth surface [2]. Faulty tooth brushing is the most common cause of abrasion. The lesion is usually rounded or ' $\mathrm{V}$ ' shaped 
Abdulaziz Algadhi; Saudi J Oral Dent Res, Mar, 2021; 6(3): 129-133

ditches located on the buccal or labial cervical area of the tooth. The most commonly affected teeth are canines and premolars [2].

Abfraction is a TW caused by eccentric occlusal loads which lead to compressive and tensile forces at the cervical area of the tooth. The lesion appears as a wedge shaped with sharp rims at the cemento-enamel junction $[1,2]$.

\section{Prevalence}

Males show more TW than females due to increased occlusal forces in males [7]. The prevalence of TW increased with age. A systematic review showed that the percentage of patients with severe TW increased from $3 \%$ at 20 years old to $17 \%$ at 70 years old [8]. Another study showed similar outcomes. In this study, the extent of TW was scored from 0 to 3 , the mean wear score increased from 0.6 in 20-29 years old group to 1.4 in 70-79 years old group [9]. In the UK, a survey ran by NHS showed increased TW from $66 \%$ in 1998 to $76 \%$ in 2009 [10].

\section{Aetiology}

Clinical diagnosis of TW is not an easy job. Dentists know that the cause of TSL is multifactorial. Therefore, the TW term, which can be used when describing the aetiology, might be only used to describe the outcome of underlying events rather than the cause of the wear [1].

During the diagnosis, a detailed patient history is important to understand the causative factors [1]. Patient might present with TW resulting from erosion and abrasion, each condition should be addressed for better prevention strategy and treatment plan.

\section{Attrition}

Tooth wear can occur physiologically with age or pathologically results of parafunctional habits. The physiological TW has been found to be 20-38 $\mu \mathrm{m}$ annually mainly as occlusal attrition [11]. It has been shown that attrition is the most common cause of tooth wear [1]. The diagnosis of this issue is difficult for the dentist, and patients sometimes are not aware of it. It has been found that the cause of bruxism is due to parafunctional activity from stress and premature contacts on mandibular movement $[12,13]$.

However, there is little evidence supporting the previous theory that premature contacts and decreased number of occluding teeth might increase the wear rate. There was no correlation between loss of teeth and tooth wear [13].

\section{Erosion}

Demineralisation of dental hard tissue takes place when the $\mathrm{pH}$ drops below 5.5 which consider the critical pH [14]. Smith and Knight found erosion in
$89 \%$ of patients referred for severe TW [15]. Erosion can be subdivided extrinsic or intrinsic $[1,2,5]$.

Extrinsic erosion includes acidic food and drinks, medication, environmental or industry related. Some medications play a role in erosive TW such as Aspirin (a salicylic acid), chewable vitamin C [7]. A relationship has been found between the consumption of acidic foods and drinks and erosion of the dental tissue $[16,17]$. Increased consumption of fizzy drinks, citrus fruits and juices and herbal tea have an erosive effect on tooth surface $[5,16,18]$. The measurement of the total acid content, which called titratable acidity, is the main indicator in determining the erosive potential of drinks instead of the actual $\mathrm{pH}$ value.

Industrial worker can have an exposure to acid in the work which lead to environmental erosion. Erosive TW has been found in industrial worker such as wine tasting and battery acid manufacturing [19, 20]. Swimming pools usually have low $\mathrm{pH}$ chlorinated water which consider a causative factor for erosive TW [21].

Chronic alcoholism causes extrinsic and intrinsic erosion. Alcohol has an acidic component which cause extrinsic erosion beside the intrinsic effects of vomiting and regurgitation [22].

Intrinsic erosion is caused by gastric content entering the oral cavity. (23) It can be voluntary or involuntary diseases or habits. Vomiting, for example, can be voluntary and involuntary due to excessive alcohol intake, during pregnancy, and side-effect of medications [1].

Gastro-intestinal disturbances such as rumination and gastro-oesophageal reflux disease (GORD) can cause involuntary regurgitation of gastric acids. The $\mathrm{pH}$ of the stomach acid is 2 which is very erosive to the dental tissues especially the palatal and lingual surfaces. Some patient might not be aware of the silent reflux until this issue seen by the dentist. Referral to the medical practitioner should be done to investigate and treat the problem that might lead to serious harm such as strictures and ulceration of oesophageal lining $[1,24]$.

Eating disorders such as bulimia and anorexia nervosa can increase the incident of voluntary regurgitation. Perimolysis lesions, which are erosion on the palatal surfaces of upper incisors, are the sign of voluntary regurgitation [25].

Rumination usually seen in mentally disable patients. It includes GORD with voluntary and involuntary regurgitation of swallowed food and then re-chewed and re-swallowed. However, the prevalence of erosion associated with rumination is not fully known [26]. 


\section{Abrasion}

Abrasive TW caused by habit such as pipe smoking, nail biting, pen-chewing and most commonly faulty toothbrushing. Aggressive toothbrushing with abrasive toothpastes can cause abrasion on the cervical area of the canines and premolars [1,2]. Also, using of interdental brushes and toothpicks improperly can cause abrasion. Eating unwashed vegetables and fruits were found to cause abrasion due to the amounts of soil they contained [27]. Dry sunflower seeds can cause abrasive TW on the incisal area of anterior teeth [28].

\section{Abfraction}

Abfraction is a TW caused by eccentric occlusal forces, leading to a tensile and compressive load on the cervical area of the tooth [2]. It has been debated whether abfraction is a form of TW or a combination of erosion, abrasion and attrition. Attrition and abrasion may accelerate the wear in the cervical area. Furthermore, erosion can cause softening of the tooth surface and increase the loss of tissue at the cervical area [29].

\section{Diagnosis of tooth wear}

It is very difficult to distinguish between the clinical presentations and causes of the TW, and these affect the diagnosis. Dentists should, however, find out if the wear is pathological or physiological. A thorough and detailed history of the chief complain should be recorded. Detailed and accurate medical history and medication used should be documented. Intraoral assessment of the signs and symptoms alongside with the location of the TW. Photographs, radiographs and salivary flow rate are a very important measures to obtain a successful diagnosis and treatment [2].

The diagnosis should include a description of the types of lesions, locations, extent, and severity of the wear [1]. Some indices have been used to grade the severity of TSL by recording the affected surface with a number. Tooth Wear Index by Smith and Knight is the most popular index [15]. This index is very useful to compare the rate of TW between patients and to monitor the progress of TSL for each patient [2]. Basic erosive wear examination (BEWE) is another method to record and monitor the TW [30]. In this method the teeth are divided into sextant, then the highest score is recorded for each sextant. Moreover, intraoral scanners can be used to diagnose and monitor TW [31].

There are different strategies help to diagnose and monitor TW. Scratch test, for example, can be used where scratch is made on the tooth structure with a blade and monitor the scratch. When the scratch disappears, the erosion or abrasion has happened. Photographs also help to monitor the changes in the translucency and shade of the teeth. Furthermore, dental casts are very important diagnostic tool to examine the changes in the wear pattern over the time [32].

\section{Prevention of TSL}

Managing acute conditions is the first line of treatment. This involve applying a desensitising agent or fluoride varnish over the exposed dentin to reduce the sensitivity. Glass ionomer can be applied as well until the definitive restoration planned. In some severe worn dentition, root canal treatment or even extraction may be needed [2].

The second stage is the prevention which include:

1. Fluoride has been found to protect the teeth from subsequent wear in case of erosive TW. Munoz et al., found that using reminerlising toothpastes increased the hardness of the exposed surface to acid comparing to conventional fluoride toothpastes [33].

2. Desensitising Agent: it has been shown that application of $0.7 \%$ fluoride at the dental office followed by application of $0.4 \%$ stannous fluoride at home reduce the sensitivity [34]. Potassium fluoride toothpaste can help in managing sensitivity. Tooth mousse from GC is a useful paste for managing sensitivity from TW which administered using bleaching tray [2].

3. Modification in beverages: it has been found that adding calcium lactate to Coca Cola reduce the erosive potential. Patient with erosive wear because of increased consumption of carbonated drinks, fruit juices or any other acidic drinks should be informed to reduce the quantity and frequency of consumption [2].

4. Changes habits such as drinking acidic drink with straw and avoid swishing it in the mouth. Stop habits like pen/pencil and nail biting [2].

5. Splints in cases of TW, splint is beneficial to prevent further loss of tooth especially from attrition [1, 2]. Patients with nocturnal bruxism, night guard is required. The splint should provide an ideal occlusion, with even centric stops, canine guidance and even anterior guidance [2].

6. Referral to medical doctor when dentist suspects any reflux disease or bulimia. Medications such as omeprazole and ranitidine can be prescribed to reduce the gastric reflux $[1,2]$.

\section{Primary investigations}

These investigations include a detailed medical and dental history, clinical assessment to find out the cause of TW. Furthermore, aesthetic, restorative, periodontal and endodontic examinations with radiographs should be made [1].

\section{Diagnostic Phase}

Mounted study casts should be used to check the overall dentition, occlusion, contacts and presence of any interferences, and availability of restorative space. The occlusal vertical dimension (OVD) should be recorded with a jaw registration at the planned new vertical dimension (Retruded Contact Position) which will be used to mount the casts on the semi-adjustable 
Abdulaziz Algadhi; Saudi J Oral Dent Res, Mar, 2021; 6(3): 129-133

articulator [1]. Then, Wax-up can be made at the new vertical dimension. At this stage, the foundation for the planned treatment can be transferred to the patient mouth to assess the vertical dimension, function and aesthetics.

\section{CONCLUSION}

TSL or TW is a common physiological condition occurs throughout the patients' life, however, excessive tooth wear that cause functional and aesthetic problems are considered pathological wear. Dentists should be aware of the aetiology of the tooth wear in order to provide a successful diagnosis, management, and treatment.

\section{REFERENCES}

1. Hemmings, K., Truman, A., Shah, S., \& Chauhan, R. (2018). Tooth wear guidelines for the bsrd part 1: aetiology, diagnosis and prevention. Dental Update, 45(6), 483-495.

2. Mehta, S. B., Banerji, S., Millar, B. J., \& SuarezFeito, J. M. (2012). Current concepts on the management of tooth wear: part 1. Assessment, treatment planning and strategies for the prevention and the passive management of tooth wear. British dental journal, 212(1), 17-27.

3. Hattab, F. N., \& Yassin, O. M. (2000). Etiology and diagnosis of tooth wear: a literature review and presentation of selected cases. International Journal of Prosthodontics, 13(2).

4. Lambrechts, P., Braem, M., Vuylsteke-Wauters, M., \& Vanherle, G. (1989). Quantitative in vivo wear of human enamel. Journal of dental research, 68(12), 1752-1754.

5. Eccles, J. D. (1982). Tooth surface loss from abrasion, attrition and erosion. Dental update, 9(7), 373-4.

6. Kelleher, M., \& Bishop, K. (1999). Tooth surface loss: an overview. British Dental Journal, 186(2), 61-66.

7. Donachie, M. A., \& Walls, A. W. G. (1995). Assessment of tooth wear in an ageing population. Journal of dentistry, 23(3), 157-164.

8. Van't Spijker, A., Rodriguez, J. M., Kreulen, C. M., Bronkhorst, E. M., Bartlett, D. W., \& Creugers, N. H. (2009). Prevalence of tooth wear in adults. Int J Prosthodont, 22(1), 35-42.

9. Bernhardt, O., Gesch, D., Splieth, C., Schwahn, C., Mack, F., Kocher, T., ... \& Kordass, B. (2004). Risk factors for high occlusal wear scores in a population-based sample: results of the Study of Health in Pomerania (SHIP). International Journal of Prosthodontics, 17(3), 333-339.

10. White, D. A., Tsakos, G., Pitts, N. B., Fuller, E., Douglas, G. V. A., Murray, J. J., \& Steele, J. G. (2012). Adult Dental Health Survey 2009: common oral health conditions and their impact on the population. British dental journal, 213(11), 567-572.
11. Lambrechts, P., Braem, M., Vuylsteke-Wauters, M., \& Vanherle, G. (1989). Quantitative in vivo wear of human enamel. Journal of dental research, 68(12), 1752-1754.

12. Ramfjord, S. P. (1961). Bruxism, a clinical and electromyographic study. The Journal of the American Dental Association, 62(1), 21-44.

13. Smith, B. G. N., \& Robb, N. D. (1996). The prevalence of toothwear in 1007 dental patients. Journal of Oral Rehabilitation, 23(4), 232-239.

14. Singh, S., \& Jindal, R. (2010). Evaluating the buffering capacity of various soft drinks, fruit juices and tea. Journal of conservative dentistry: JCD, 13(3), 129.

15. Smith, B. G. (1984). An index for measuring the wear of teeth. Br Dent J, 156, 435-438.

16. Jarvinen, V. K., Rytomaa, I. I., \& Heinonen, O. P. (1991). Risk factors in dental erosion. Journal of dental research, 70(6), 942-947.

17. Lussi, A. (2006). Erosive tooth wear-a multifactorial condition of growing concern and increasing knowledge. In Dental erosion (Vol. 20, pp. 1-8). Karger Publishers.

18. Phelan, J., \& Rees, J. (2003). The erosive potential of some herbal teas. Journal of dentistry, 31(4), 241-246.

19. Mulic, A., Tveit, A. B., Hove, L. H., \& Skaare, A. B. (2011). Dental erosive wear among Norwegian wine tasters. Acta Odontologica Scandinavica, 69(1), 21-26.

20. Tuominen, M. L., Tuominen, R. J., Fubusa, F., \& Mgalula, N. (1991). Tooth surface loss and exposure to organic and inorganic acid fumes in workplace air. Community dentistry and oral epidemiology, 19(4), 217-220.

21. Geurtsen, W. (2000). Rapid general dental erosion by gas-chlorinated swimming pool water. Review of the literature and case report. American journal of dentistry, 13(6), 291-293.

22. Smith, B. G. N., \& Robb, N. D. (1989). Dental erosion in patients with chronic alcoholism. Journal of Dentistry, 17(5), 219-221.

23. Johansson, A. K., Omar, R., Carlsson, G. E., \& Johansson, A. (2012). Dental erosion and its growing importance in clinical practice: from past to present. International journal of dentistry, 2012.

24. Reid, B. J., Weinstein, W. M., Lewin, K. J., Haggitt, R. C., VanDeventer, G., DenBesten, L., \& Rubin, C. E. (1988). Endoscopic biopsy can detect high-grade dysplasia or early adenocarcinoma in Barrett's esophagus without grossly recognizable neoplastic lesions. Gastroenterology, 94(1), 81-90.

25. Schmidt, U., \& Treasure, J. (1997). Eating disorders and the dental practitioner. The European journal of prosthodontics and restorative dentistry, 5(4), 161-167.

26. Milosevic, A. (1999). Eating disorders and the dentist. British dental journal, 186(3), 109-113. 
27. Levrini, L., Di Benedetto, G., \& Raspanti, M. (2014). Dental wear: a scanning electron microscope study. BioMed Research International, 2014.

28. Warreth, A., Abuhijleh, E., Almaghribi, M. A., Mahwal, G., \& Ashawish, A. (2020). Tooth surface loss: A review of literature. The Saudi dental journal, 32(2), 53-60.

29. Bartlett, D. W., \& Shah, P. (2006). A critical review of non-carious cervical (wear) lesions and the role of abfraction, erosion, and abrasion. Journal of dental research, 85(4), 306312.

30. Bartlett, D., Ganss, C., \& Lussi, A. (2008). Basic Erosive Wear Examination (BEWE): a new scoring system for scientific and clinical needs. Clinical oral investigations, 12(1), 65-68.
31. Kumar, S., Keeling, A., Osnes, C., Bartlett, D., \& O'Toole, S. (2019). The sensitivity of digital intraoral scanners at measuring early erosive wear. Journal of dentistry, 81, 39-42.

32. Kaidonis, J. A. (2012). Oral diagnosis and treatment planning: part 4. Non-carious tooth surface loss and assessment of risk. British dental journal, 213(4), 155-161.

33. Munoz, C. A., Feller, R., Haglund, A., Triol, C. W., \& Winston, A. E. (1999). Strengthening of tooth enamel by a remineralizing toothpaste after exposure to an acidic soft drink. The Journal of clinical dentistry, 10(1 Spec No), 17-21.

34. Thrash, W. J., Dodds, M. W., \& Jones, D. L. (1994). The effect of stannous fluoride on dentinal hypersensitivity. International dental journal, 44(1 Suppl 1), 107-118. 